\title{
A organização dos serviços de Atenção Primária à Saúde no Brasil
}

The organization of

Primary Care in Brazil

Carlos Eduardo Aguilera Campos ${ }^{1}$

\section{RESUMO}

Múltiplos aspectos relacionados à formulação de políticas, à construção do conhecimento e à implementação das práticas no setor de saúde interagem mutuamente e têm como produto a maneira como se prestam os serviços de saúde em certo contexto histórico ou, ainda, resultam na disponibilidade ou escassez de um determinado conjunto de ações e serviços de saúde. Compreender essas relações é fundamental para se avaliar a trajetória da política de saúde no país.

O surgimento e a consolidação da rede básica voltada para as ações de Atenção Primária à Saúde no Brasil se materializaram por meio da criação de uma rede permanente de Centros de Saúde. A trajetória histórica desses serviços é analisada tomando-se como referência seus princípios organizativos e assistenciais, sua expansão em termos físicos e sua função no Sistema Público de Saúde. Por fim, são descritas as principais tendências atuais da Atenção Primária à Saúde no atual contexto do SUS, tanto do ponto de vista da organização quanto das suas funções e do financiamento.

\section{ABSTRACT}

Multiple aspects related to policy-making, knowledge building and implementation of care practices interact mutually in the health sector. The product of these interactions is the way health services are provided in a certain historical context or still the availability or lack of a determinate set of health actions and services. To understand these relations is pivotal for evaluating the course the health policies took in our country.

In Brazil, the emergence and consolidation of the basic network engaged in Primary Care occurred with the creation of a permanent network of Health Centers. This paper analyzes the historical trajectory of these services, taking as a reference their organizational and assistance principles, their expansion in terms of physical growth and their function within the Public Health System. Finally, the main trends in Primary Care in the today's context of the Unified Health System (Sistema Único de Saúde-SUS) are described from the organizational viewpoint and from the perspective of its functions and funding.

PALAVRAS-CHAVE:

- Política de Saúde;

- Sistema de Saúde;

- Atenção Primária à Saúde.
KEY-WORDS:

- Health Policy;

- Health System;

- Primary Health Care.

${ }^{1}$ Doutor em Medicina Preventiva, Prof. Adjunto, Programa de Atenção Primária à Saúde, Faculdade de Medicina, Universidade Federal do Rio de Janeiro, Rio de Janeiro, Brasil.

131 Rev Bras Med Fam e Com Rio de Janeiro, $v .2, n^{\circ} 6$, jul $/$ set 2006 


\section{A Gênese da Rede Básica: o surgimento de estabelecimentos de Saúde Pública no Brasil.}

Os primeiros estabelecimentos que objetivavam prestar assistência com foco na Saúde Pública surgem em 1916. Cabe salientar que, anteriormente a este período, existiam Delegacias de Saúde, as quais tinham como principal função coordenar o trabalho dos profissionais em diversos setores, tais como a inspeção sanitária de estabelecimentos e habitações, o controle de alimentos e bebidas, as campanhas de vacinação, o suporte laboratorial etc. Estas eram distribuídas estrategicamente em bairros centrais das principais cidades e funcionavam sobretudo como apoio logístico e administrativo às equipes. Muitas foram as razões que levaram à criação dos primeiros estabelecimentos de saúde pública voltados para o atendimento ao cidadão. Dentre elas, pode-se destacar a ampliação de responsabilidades e das atribuições da Saúde Pública, que passou a atuar nas áreas de saneamento, propaganda sanitária, higiene infantil, higiene industrial e, neste momento, especialmente, no combate às endemias rurais ${ }^{1}$. Além disso, novos instrumentos diagnósticos, de profilaxia e imunização, permitiam a atuação mais direta no combate às doenças. Esta mudança tinha como premissa a necessidade de dotar o governo de uma administração moderna e de buscar um enfrentamento mais efetivo das doenças endêmicas e epidêmicas. Os Postos de Saneamento e Profilaxia Rural passam a representar esta nova fase, dedicados a prestar assistência, de forma permanente, a populações definidas. Antes de 1916, devido à escassez de pessoal técnico, não havia postos permanentes, mas apenas as célebres expedições de médicos sanitaristas ao interior do país ou ainda iniciativas mais ou menos isoladas, compostas por comissões voluntárias, sem bases institucionais definidas. Estas ações não pareciam alterar consubstancialmente o dramático quadro de saúde em que se encontrava a população brasileira. Carlos Chagas começou a implantar os Postos de Saneamento e Profilaxia Rural com o objetivo de combater, em cada local, determinadas doenças consideradas prioritárias:

"A partir de 1916, o governo brasileiro inaugura os primeiros postos de profilaxia rural na periferia da cidade do Rio de Janeiro. Este projeto, que priorizava o combate a doenças como a malária, a ancilostomose e a doença de Chagas, expande-se e atinge diversos pontos do interior do país, durante a gestão de Carlos Chagas." 2

Essas estruturas progressivamente se disseminaram no país, a partir da criação do Serviço de Profilaxia Rural, em 1918. Com o apoio da Fundação Rockefeller, Postos de Saneamento e Profilaxia Rural foram sendo implantados nas capitais e no interior dos estados. A necessidade de se constituir um corpo técnico a desempenhar as novas funções não foi negligenciada. Médicos Sanitaristas e Enfermeiras Visitadoras eram considerados recursos estratégicos para essa nova política.

Todo o trabalho desenvolvido nos Postos de Saneamento e Profilaxia Rural e de formação de recursos humanos serviram de base para o passo seguinte: a criação dos Centros de Saúde, unidades mais complexas, que se tornaram, por sete décadas, as unidades consagradas à atuação da Atenção Primária à Saúde no Brasil.

A implantação dos primeiros Centros de Saúde data do ano de 1925, quando foram instalados três estabelecimentos na capital paulista: o Centro 
de Saúde do Brás, o Centro de Saúde do Bom Retiro e o Centro de Saúde do Instituto de Hygiene, este último, considerado estabelecimento modelo. Uma publicação a respeito dos documentos confidenciais do Rockefeller Archive Center (EUA) apresenta carta de Paula Souza, datada de 19 de junho de 1925:

"Informa que os Centros de Saúde têm funcionado muito bem, de modo integrado, sem as antigas divisões (uma para doença venérea, outra para puericultura etc). Agora os especialistas dedicam-se em horários diversos a suas especialidades, mas sem prejudicar o caráter geral dos trabalhos, tanto mais que muitos poucos são verdadeiros higienistas. Explica que as discussões realizadas no Congresso de Higiene, em Belo Horizonte (II Congresso Brasileiro de Higiene, 1924), confirmaram que não há vantagens em conservar os postos nos moldes antigos dos postos de profilaxia rural, criados para controle de doenças endêmicas específicas" ${ }^{3}$

A intenção era reservar a denominação Centro de Saúde para as unidades de maior complexidade, instaladas em núcleos urbanos, porém, realizando reformas que viessem a modernizar os antigos Postos de Saneamento e Profilaxia Rural. A posse de Clementino Fraga no Departamento Nacional de Saúde, em novembro de 1926, viabilizou a implantação do primeiro Centro de Saúde no Distrito Federal. Juntamente com João de Barros Barreto e José Paranhos Fontenelle, ele inaugurou, no dia $1^{\circ}$ de janeiro de 1927 , o Centro de Saúde de Inhaúma.

As vantagens enaltecidas por Clementino
Fraga $^{4}$, quando da inauguração do Centro de Saúde de Inhaúma, eram principalmente de natureza gerencial e administrativa. Segundo ele, em vez da divisão por funções, em que cada uma das repartições sanitárias era especializada em uma doença endêmica, fazia-se mister, especialmente em uma grande cidade como o Rio de Janeiro, um sistema de divisão por tarefas, centralizadas todas em um mesmo distrito, que aglutinasse as diversas repartições, antes dispersas, em um local acessível às populações.

"Dahi o novo systema de administração que nos últimos tempos vae fazendo caminho em substituição à divisão por funcções, creando-se em cada districto uma repartição sanitaria local, pela concentração, em um mesmo edificio, de todos os dispensários dessa zona e de outros serviços de Saúde Pública sob a chefia de um sanitarista" 4.

Propunha-se a disseminação desta organização sanitária por toda a capital. Nos Centros de Saúde, previa-se a instalação dos seguintes serviços internos entre os chamados dispensários e escriturários: Administração, Registro, Estatística e Propaganda; Pré-natal; Higiene da Criança; Tuberculose; Doenças Venéreas; Lepra; Saneamento e Polícia Sanitária; Higiene da Alimentação; Higiene do Trabalho; Exames de Saúde; Laboratório 5 .

Os Centros de Saúde eram uma evolução das teorias administrativas em voga na segunda metade da década de 1920. Representavam uma nova forma de organização que passou a ser defendida com muita ênfase, fruto da reiterada influência da Fundação Rockefeller. Esse período pode ser denominado de Nova Higiene, e os representantes 
dessas novas propostas ficaram conhecidos, no Brasil, pelo nome de Jovens Turcos*. Esse movimento de renovação sanitária tinha como objetivo transformar a atuação então vigente, de polícia sanitária, em práticas dotadas de nova concepção, de cunho mais educativo e preventivo, de modo a criar uma nova consciência sanitária nos indivíduos e nas famílias. Essa era a base da atuação dos Centros de Saúde e exigia uma mudança organizacional na área da Saúde Pública.

A nova forma de atuação, por meio dessa rede local permanente de unidades de saúde, abrangeu duas novas metodologias ou ferramentas. Foram elas: a subdivisão das cidades em Distritos Sanitários para a ação das equipes e a Educação Sanitária às famílias. Por meio das visitas domiciliares sistemáticas, buscava-se monitorar e traçar o perfil epidemiológico de cada área. A partir de tal conhecimento, passava-se a atuar segundo as técnicas de prevenção e profilaxia disponíveis e a transmitir às famílias novos hábitos de higiene.

Outra vertente científica e filosófica não menos importante a nortear esses modernos estabelecimentos sanitários foi a Educação Sanitária. Os novos sanitaristas defendiam que somente com uma nova consciência dos cidadãos seria possível superar as mazelas sanitárias do país. A ignorância, mais do que a pobreza ou as péssimas condições de vida, era tida como um fator que pesava decisivamente para a alta incidência de doenças infecto contagiosas. A Educação consistia na principal ferramenta para combater a disseminação das doenças. Esse ideário estava relacionado a uma nova conformação política do país, com o enfraquecimento do regime oligárquico e a presença cada vez mais forte das classes médias urbanas no cenário político-econômico. Com o aumento considerável das populações urbanas, a atuação sanitária se fazia necessária não só sobre o meio ambiente, mas considerava-se prioridade a estratégia para alcançar as rotas privadas da infecção, buscando notificar, controlar e orientar famílias e indivíduos. Há que se destacar que a prioridade em termos do espaço urbano era o combate à tuberculose, cuja incidência crescia em escala alarmante. A concepção de um novo espaço em que pudesse funcionar com vários dispensários em horários alternados, sob a chefia de um médico sanitarista e o esquadrinhamento do território urbano por meio da distritalização, poderia possibilitar conhecer, em tempo real, a evolução das principais doenças, assim como os problemas relacionados à saúde materno-infantil, tornando possível medidas eficazes de controle e profilaxia. Por meio das Enfermeiras Visitadoras, esse novo modelo permitia implementar um moderno modelo de quarentena, circunscrevendo a atuação dos profissionais no âmbito das famílias e domicílios.

\section{II- A evolução da rede de Atenção Primária à Saúde no Brasil}

A rede de Centros de Saúde foi, na sua gênese, uma proposta de grupos "tecnoburocráticos". Apesar de buscarem consolidar uma organização pautada na eficiência e na racionalidade, muitas foram as fontes de pressão política que se

\footnotetext{
*Segundo o Prof. Lúcio Costa, Presidente da Sociedade Brasileira de Higiene, este termo foi cunhado tendo como referência o então processo de ocidentalização da Turquia, que acabou com algumas das tradições milenares daquele país. Os jovens sanitaristas desejavam modernizar a Saúde Pública brasileira, daí o termo ter sido cunhado e se popularizado quando se fazia referência ao grupo. (NR)
} 
manifestaram contra ou a favor do seu papel institucional, de acordo com interesses representados na sociedade brasileira. Não obstante, diversas diretrizes advindas de gestores do setor buscaram imprimir sua lógica e alcançaram, progressivamente, o objetivo de fazer essa organização desempenhar algumas das funções defendidas pelos seus idealizadores. Geraram-se, por fim, mudanças na estrutura e no funcionamento do sistema de saúde, mesmo que suscitando, ora reações de adesão, ora resistências, de acordo com maior ou menor coerência entre as suas proposições e as políticas vigentes. Mas, de uma maneira geral, o que se deu foi uma progressiva consolidação da organização dos Centros de Saúde.

Pode-se afirmar que as organizações estruturam um determinado funcionamento que se mantém por longos períodos, anos ou décadas. Daí o consenso de que as estruturas burocráticas tendem invariavelmente à inércia. Esse processo usualmente se caracteriza pela formação de culturas organizacionais. Na primeira fase, os Centros de Saúde eram a proposta de uma rede básica permanente que deveria estar próxima às comunidades e que combatesse a ignorância do povo a respeito da higiene e, especialmente, a inoperância da Saúde Pública frente aos novos desafios colocados pela urbanização e industrialização do país. Apresentavam um status de agenda propositiva, ao terem sido minuciosamente planejados por sanitaristas que, àquela época, passavam a ocupar cargos na organização sanitária federal, fundando um novo marco da organização sanitária brasileira. Além disso, no momento da constituição dessa rede, o país tinha como flagelo sanitário em suas áreas urbanas um quadro de morbi- mortalidade que assegurou legitimidade a essa nova proposta: a tuberculose, as doenças venéreas, as doenças materno-infantis. Esse quadro representava um desafio não passível de solução pela estrutura sanitária até então vigente, o que fortaleceu a idéia de que a organização dos Centros de Saúde pudesse transformar-se em instrumento de mudanças.

A necessidade de consolidar a influência do poder central nas diversas unidades da Federação fez com que a antiga ênfase dada às ações sanitárias na Capital da República fosse revista. Esse período coincide com a implantação da rede de Centros de Saúde em todas as capitais do país e nas cidades de médio porte ${ }^{6}$, como pode ser visto na tabela 1.

Entre as décadas de 50 e 70, a expansão e a prioridade dadas a essa rede local permanente foram colocadas em um segundo plano, transformando-se em uma organização mais conservadora, atuando de maneira rígida e quase ritualista, como nos casos da emissão de carteiras de saúde para trabalhadores e escolares. Essa etapa coincidiu com o crescimento da medicina previdenciária e o surgimento dos grandes hospitais e ambulatórios dos Institutos de Aposentadorias e Pensões. Foi a era do crescimento do complexo médicoindustrial.

Um novo surto de crescimento da rede básica se deu no início dos anos 1980, decorrente do processo de redemocratização do país. A sociedade brasileira lutava pela consolidação de seus direitos sociais e, por conseguinte, pelo direito dos excluídos à assistência à saúde. Em um contexto de crise do modelo da saúde previdenciária, que acarretou fortes medidas de racionalização do gasto em saúde, privilegiou-se a Atenção Primária 
Tabela 1. Unidades Sanitárias Existentes no País em 1942 - Divisão de Organização Sanitária - DNS:

\begin{tabular}{|c|c|c|c|c|c|c|c|c|}
\hline $\begin{array}{l}\text { Estados, Territórios } \\
\text { e Distrito Federal }\end{array}$ & $\begin{array}{l}\text { Distritos } \\
\text { Sanitários }\end{array}$ & $\begin{array}{l}\text { Centros } \\
\text { de Saúde }\end{array}$ & $\begin{array}{c}\text { Postos } \\
\text { de Higiene } 1\end{array}$ & $\begin{array}{c}\text { Postos } \\
\text { de Higiene } 2\end{array}$ & Sub-Postos & $\begin{array}{c}\text { Postos } \\
\text { Especializados }\end{array}$ & $\begin{array}{l}\text { Postos } \\
\text { Itinerantes }\end{array}$ & $\begin{array}{c}\text { População } \\
\text { Distrito / } 1000\end{array}$ \\
\hline Acre & 7 & - & - & - & 7 & - & - & 12 \\
\hline Amazonas & 6 & 1 & - & - & 2 & - & - & 75,5 \\
\hline Pará & 7 & 2 & - & - & 7 & - & - & 137 \\
\hline Maranhão & 6 & 1 & - & 2 & 4 & - & 6 & 207 \\
\hline Piauí & 3 & 1 & - & 2 & 16 & - & - & 275 \\
\hline Ceará & 4 & 1 & 4 & 6 & - & 3 & 2 & 525 \\
\hline Rio G. do Norte & 11 & 1 & - & 1 & 3 & - & - & 70,5 \\
\hline Paraíba & - & 1 & 1 & 6 & 10 & - & - & - \\
\hline Pernambuco & 10 & 4 & 2 & 13 & 32 & - & 4 & 269 \\
\hline Alagoas & 10 & 1 & - & 4 & - & - & - & 191 \\
\hline Sergipe & 7 & 1 & - & - & 6 & - & - & 78 \\
\hline Bahia & 10 & 3 & - & 11 & 44 & 4 & - & 394 \\
\hline Espírito Santo & 7 & 1 & 1 & 5 & 1 & 2 & 1 & 108 \\
\hline Rio de Janeiro & 11 & 2 & 3 & - & 57 & - & - & 169 \\
\hline Distrito Federal & 15 & 15 & - & - & - & - & - & 116 \\
\hline São Paulo & 93 & 7 & 2 & 8 & 77 & - & - & 78 \\
\hline Paraná & 6 & 1 & 1 & 17 & 30 & - & - & 208 \\
\hline Santa Catarina & 7 & 1 & 4 & 2 & - & - & - & 169 \\
\hline Rio G. do Sul & 88 & 5 & 35 & 32 & - & - & - & 38 \\
\hline Minas Gerais & 26 & 1 & - & 25 & - & 4 & - & 261 \\
\hline Mato Grosso & 9 & 1 & - & - & 8 & - & - & 48 \\
\hline Goiás & 7 & - & 1 & 6 & - & - & - & 119 \\
\hline Total & 350 & 51 & 54 & 140 & 304 & 13 & 13 & \\
\hline
\end{tabular}

Fonte: Barros Barreto, $1942^{6}$

à Saúde e a municipalização da prestação de serviços de saúde. Essas medidas estavam respaldadas pela Conferência de Alma Ata, que preconizava um rol de cuidados essenciais a serem prestados aos povos, de forma a se alcançar saúde para todos. Estavam dadas, assim, as novas bases políticas e técnicas para o surgimento de um novo surto de crescimento e desenvolvimento da rede básica.

O movimento da Reforma Sanitária estimulou inúmeras iniciativas de governos municipais ${ }^{7}$. Via de regra, as ações envolviam a rede básica, que se expandiu com a implantação de novas unidades em comunidades de baixa renda. Em contraposição aos serviços da previdência social, propunha-se, com essa nova rede, a reformulação da lógica assistencial de todo o sistema sanitário, privilegiando a universalização da assistência, a integralidade das ações de saúde e a democratização da gestão setorial.

Os Centros e Postos de Saúde passaram a ser privilegiados como estabelecimentos sanitários destinados a prestar serviços básicos à população, agora, não só em atividades de prevenção e realização de exames periódicos. Passouse também a prestar assistência nas áreas básicas: clínica, pediatria e gineco-obstetrícia. Esse processo de descentralização da saúde previdenciária e da subseqüente municipalização do sistema de saúde brasileiro se consolidou definitivamente com a promulgação da Constituição de 1988 e a criação do Sistema Único de Saúde (SUS). 
Modernas ferramentas e tecnologias foram introduzidas durante esse período de reestruturação da rede de Centros e Postos de Saúde no País. O desenvolvimento do Planejamento em Saúde na América Latina possibilitou a elaboração de novos modelos de intervenção com o objetivo de reduzir os agravos à saúde e as mortes evitáveis. Com base em análises de magnitude, transcendência, vulnerabilidade das doenças e do custo-efetividade de instrumentos e atividades, a rede básica passou a ofertar ações de caráter preventivo, segundo a lógica da Programação em Saúde. Esta pode ser definida como:

"O conjunto de práticas que, a partir de um referencial epidemiológico, tomam como seu objeto de intervenção a saúde e a doença no coletivo, utilizando como instrumento de intervenção diversas atividades que são articuladas e organizadas no sentido de produzirem um efeito sobre a saúde no plano coletivo" 8 .

Os Programas de Saúde buscaram, em outras palavras, com base em prioridades elegíveis segundo critérios acima citados, combinar tecnologias e intervenções de caráter clínicoepidemiológicas calcadas em medidas de impacto, eficácia, efetividade e eficiência comprovadas. Tais ações passaram a ser a parte mais visível do trabalho das unidades básicas. É inegável terem alcançado progressos, que se refletiram em meIhorias de determinados indicadores sanitários. Além disso, em diversos setores sociais, houve respaldo e legitimidade necessários à sua continuidade. Dentre essas ações, destacaram-se os programas de combate à desnutrição e à diarréia na infância, de prevenção da AIDS, de imunizações, de prevenção do câncer de mama e de colo uterino, de aleitamento materno, de controle da hipertensão e do diabetes.

Ainda assim, não se pode afirmar que o sistema como um todo sofreu as transformações substanciais esperadas nem que tenha correspondido aos anseios da população, pois muitos problemas ainda persistiram. Com relação aos Programas de Saúde, a opção por operá-los tomando por base as especialidades de cada área técnica acarretou na fragmentação do trabalho desenvolvido nas unidades básicas. Geralmente, onde existia o recurso disponível, o cardiologista atuava no programa de controle da hipertensão, o pneumologista, no programa de controle da tuberculose, o dermatologista, no programa de controle da hanseníase e assim por diante. Os demais profissionais, especialmente de enfermagem, distribuíram-se segundo as "especialidades", cada um cuidando de seu próprio campo de atuação, sem integração uns com os outros. Impasses decorrentes dessa forma de atuar eram evidentes. Reproduziu-se um atendimento especializado, muito próprio do ambiente hospitalar, comprometendo as premissas da Atenção Primária à Saúde, do vínculo entre usuários, famílias e profissionais. As dificuldades em se dotar cada um dos Centros e Postos de Saúde com recursos suficientes para operar cada programa foram notórias nesse modelo, de tal forma que, por exemplo, unidades possuíam atendimento da criança, às segundas e sextas-feiras pela manhã, de clínica médica, às terças e quintas-feiras, da mulher, às quartas-feiras, e assim por diante. Os Programas voltados para as doenças infecto contagiosas também 
seguiram a mesma lógica de fragmentação e especialização. Perdeu-se quase por completo, com raras exceções, a noção de território, de vínculo entre a equipe e a comunidade.

Contribuíram ainda para aprofundar essa fragmentação as medidas, sempre urgentes, de estender a cobertura assistencial, contratando-se de profissionais para realizar, nas unidades básicas, consultas médicas ambulatoriais sem qualquer planejamento para adequá-las aos problemas de saúde locais. Estas foram, freqüentemente, organizadas na modalidade de pronto atendimento, sempre em número insuficiente e sem vínculo algum entre as equipes e os indivíduos. Assim, realizou-se um trabalho paralelo à lógica da programação em saúde, buscando responder às demandas dos indivíduos que não eram atendidos pelas ações programáticas. A esses problemas foram acrescentadas, ainda, a falta de treinamento dos profissionais para trabalhar segundo os princípios da Atenção Primária à Saúde e a baixa remuneração. Em conseqüência, em vez do espaço comunitário - no qual se devia buscar a integralidade, isto é, a integração das ações assistenciais e curativas, bem como de promoção e prevenção à saúde -, passou a ser comum a existência de filas de pacientes, desde a madrugada, em busca de uma "ficha" para atendimento com um especialista. Parece haver, nesses casos, a transposição da lógica dos serviços de emergência e de urgência ao trabalho da Atenção Primária à Saúde.

"O trabalho nos estabelecimentos de saúde e entre eles, na Unidade Básica, é organizado, tradicionalmente, de forma extremamente parcelada. Em eixo verticalizado, organiza-se o trabalho do médico e, entre estes, o de cada especialidade médica. Assim, sucessivamente, em colunas verticais vai se organizando o trabalho de outros profissionais. Essa divisão do trabalho se dá, de um lado, pela consolidação nos serviços de saúde das corporações profissionais e, por outro, no caso dos médicos, pela especialização do saber e, conseqüentemente, do trabalho em saúde. A organização parcelar do trabalho fixa os trabalhadores em uma determinada etapa do projeto terapêutico. A superespecialização, o trabalho fracionado, fazem com que o profissional de saúde se aliene do próprio objeto de trabalho. Desta forma, ficam os trabaIhadores sem interação com o produto final da sua atividade laboral, mesmo que tenham dele participado, pontualmente. Como não há interação, não haverá compromisso com o resultado do seu trabaIho". ${ }^{9}$

Além da segmentação, havia ainda o problema da atitude dos profissionais, especialmente do médico, cujo trabalho era marcado pelo distanciamento com relação aos interesses dos usuários, bem como pelo isolamento com relação aos outros trabalhadores da saúde e pelo predomínio de modalidades de intervenção centradas nas tecnologias duras, isto é, por um modelo assistencial voltado para a produção de ações com base em procedimentos:

"O trabalho médico orientado por este modelo se isola dos outros trabalhos em saúde, vai se especializando à introdução de cada novo tipo de associação entre procedimentos e máquinas, vai necessitando de uma autonomia que o separa das outras modalidades de abordagem em saúde e alimenta-se de uma organização corporativa poderosa, voltada, eticamente, para si mesma. Desta maneira, estas intenções que comandam o 
trabalho médico comprometido com a produção de procedimentos estão articuladas com um exercício da autonomia no trabalho clínico totalmente voltado para interesses privados estranhos aos dos usuá- rios, e isolado de um trabalho mais coletivo no in- terior das equipes de saúde, fechado e protegido no espaço físico dos consultórios, em nome de uma eficácia e de uma ética que não se sustentam em nenhum dado objetivo, em termos da produção da saúde."10

Muitas dessas distorções não aconteceram apenas no Brasil. Em vários países, os problemas com que se depararam os sistemas nacionais de saúde se circunscreveram em um dilema entre a necessidade de tornar universal a assistência médica de qualidade e a constante busca de contenção do aumento do gasto público e privado no setor, pois o modelo atual de atenção médica leva, inexoravelmente, ao problema do aumento sempre crescente de custos. O mito da imortalidade e do poder mágico da Medicina se mantém no inconsciente coletivo, a despeito de todas as evidências contrárias. O leque de opções por novas tecnologias e produtos, sempre em evolução, estimula um consumo individual sem precedentes, de forma acrítica, sem que haja uma comprovação clara de sua efetividade com relação a procedimentos anteriormente adotados.

Tanto a ampliação de cobertura da Atenção Primária à Saúde quanto a estratégia de melhorar a relação custo-efetividade, contida na lógica da Programação em Saúde, foram tentativas de resposta a esse dilema. De fato, em que pese a heterogeneidade do sistema de saúde brasileiro, composto de uma complexa mistura público/ privado, ganhou hegemonia, na estratégia de estruturação do SUS, a Atenção Primária à Saúde, com o fortalecimento e a disseminação da rede básica, de responsabilidade do poder municipal. Ainda que tal evolução tenha contribuído para a melhoria do acesso e da cobertura às ações de saúde, muitas vezes essa forma de atuação do setor público governamental foi vista como uma política de focalização, uma espécie de fornecimento de uma cesta básica sanitária, destinada a atender, como mais um programa social de caráter compensatório, os grupos mais carentes e desvalidos da população.

\section{Perfil atual da Rede Básica no Brasil}

Obedecendo a uma antiga definição utilizada pelo IBGE até 1992, os Centros de Saúde eram aqueles estabelecimentos caracterizados por prestar assistência médica em clínicas básicas (clínica médica, pediatria, ginecologia e obstetrícia), desenvolvendo atividades ambulatoriais programadas para uma população definida, bem como o controle e a prevenção de doenças e de fatores de risco associados a problemas de saúde. Diferenciavam-se dos Postos de Saúde por possuírem profissionais de nível superior em regime de trabalho permanente em sua equipe.

Foram cadastrados, em 1992, 14.763 Centros de Saúde que responderam por $46,5 \%$ das consultas ambulatoriais prestadas no país. Eles eram, portanto, o principal estabelecimento na prestação desse tipo de serviço no Brasil. Outro dado relevante era a existência de somente 286 unidades privadas $(1,9 \%)$, sendo as restantes de natureza pública, em sua maioria administradas pelos municípios $(74,8 \%)$. Entre os mais de cinco mil municípios, apenas 604 deles não o possuíam e estavam 
concentrados nos estados do Amazonas, Pará, Piauí, Maranhão e Tocantins. Os Centros de Saúde provavelmente eram inexistentes nesses locais pela falta de profissionais de nível superior em suas circunscrições, possuindo certamente Postos de Saúde. O número de Centros de Saúde cresceu a uma taxa de $12,7 \%$ ao ano desde 1980 , demonstrando uma tomada de decisão política e um consenso em torno da sua importância para o sistema de saúde municipalizado. ${ }^{11}$

Já com relação aos Postos de Saúde, estes guardavam os mesmos objetivos com relação à assistência básica programada para populações definidas, como citado acima, mas diferenciavamse dos Centros de Saúde por não possuírem profissionais de nível superior em seu quadro permanente. Eram a maioria dos estabelecimentos básicos nas regiões Norte e Nordeste, e seu índice cresceu $6 \%$ ao ano desde 1980 . Seu número absoluto era de 8.556 estabelecimentos no país, em 1992.

Os dados apresentados pelo IBGE não permitem analisar diferenças dos serviços com relarelação à sua oferta de atividades ou, muito menos, na sua composição de recursos tanto materiais quanto humanos. Tais desigualdades certamente existiam. É possível, porém, pressupor certa homogeneidade entre eles, especialmente no que diz respeito ao entendimento sobre a sua função no conjunto da rede pública de serviços de saúde e sua proposta programática. Nem mesmo as tentativas de flexibilização do caráter público e estatal das unidades de saúde, notadamente os hospitais, durante a década de 1990, colocaram em questão o status destas unidades, que unanimemente eram e são consideradas de natureza pública e estatal face aos seus objetivos, às suas funções e ao seu público alvo.

O IBGE publicou em 2002 uma nova versão da pesquisa Assistência Médico-Sanitária ${ }^{12}$. O antigo critério utilizado para a classificação de unidades básicas foi abandonado. Desta feita, foram classificadas como unidades públicas com o perfil de atenção básica e subclassificadas como gerais aquelas unidades ambulatoriais que prestam assistência nas cinco áreas básicas, quais sejam: cirurgia, ginecologia e obstetrícia; clínica médica; pediatria. As unidades subclassificadas em "com especialidades" foram aquelas que prestavam atenção em outras para além das cinco especialidades básicas e, como especializada, tinham apenas uma delas como foco principal.

Como pode ser visto na Tabela 2, mesmo com a mudança nos critérios de classificação do IBGE, pode-se afirmar que a rede básica continuou experimentando um crescimento alto e sustentado, incorporando, inclusive, as antigas unidades ambulatoriais da previdência social, que passaram, em muitos casos, a funcionar segundo os pressupostos da APS em sua prática assistencial. Das 23.323 unidades básicas existentes em 1992, passou-se a 35.759 estabelecimentos de saúde com perfil de atenção básica em 2002, o que representou um crescimento de $65 \%$. As Unidades de Saúde da Família estavam incluídas neste quantitativo, sendo, provavelmente, aquelas classificadas como gerais, no levantamento do IBGE de 2002, e como Postos de Saúde, no levantamento de 1999. Tal presunção não pode ser comprovada nos dados disponíveis no IBGE, mas é uma constatação a partir do que vem ocorrendo na maioria dos municípios brasileiros, que buscaram adequar as antigas instalações 
dos Postos de Saúde às exigências da Estratégia Saúde da Família. O esforço de reorganização do modelo de atenção à saúde no Brasil apresentou novas perspectivas desde a implantação da Estratégia de Saúde da Família (PSF). Iniciado em 1994 e sendo seu antecedente mais próximo o Programa de Agentes Comunitários de Saúde (PACS), implantado em 1991, vem se estendendo a todos os estados e à grande maioria dos municípios do país: em abril de 2005, havia 24.564 equipes de Saúde da Família implantadas em 5.242 municípios, representando $94,2 \%$ dos municípios brasileiros e oferecendo cobertura a $44,4 \%$ da população $(78.617 .526 \text { habitantes })^{13}$.

A redefinição do modelo assistencial foi importante para corrigir os problemas anteriormente apontados. A equipe mínima previa a contratação de médicos de família e comunidade. A

Tabela 2. Estabelecimentos de Saúde Públicos Sem Internação Segundo os Estados - IBGE - 2002 - Brasil:

\begin{tabular}{|c|c|c|c|c|}
\hline Estados & Especializado & C/ Especialidades & Geral & Total \\
\hline Rondônia & 19 & 8 & 417 & 444 \\
\hline Acre & 35 & 15 & 211 & 261 \\
\hline Amazonas & 10 & 16 & 539 & 565 \\
\hline Roraima & 15 & 20 & 159 & 194 \\
\hline Pará & 102 & 24 & 1.291 & 1.417 \\
\hline Amapá & 5 & 41 & 140 & 186 \\
\hline Tocantins & 17 & 55 & 325 & 397 \\
\hline Maranhão & 29 & 69 & 1.220 & 1.318 \\
\hline Piauí & 17 & 69 & 986 & 1.072 \\
\hline Ceará & 88 & 70 & 1.619 & 1.777 \\
\hline Rio G. do Norte & 24 & 81 & 698 & 803 \\
\hline Paraíba & 24 & 81 & 1.014 & 1.119 \\
\hline Pernambuco & 73 & 88 & 1.461 & 1.622 \\
\hline Alagoas & 9 & 104 & 655 & 768 \\
\hline Sergipe & 17 & 148 & 463 & 628 \\
\hline Bahia & 49 & 152 & 2.194 & 2.395 \\
\hline Minas Gerais & 806 & 155 & 2.467 & 3.428 \\
\hline Espírito Santo & 44 & 168 & 634 & 846 \\
\hline Rio de Janeiro & 211 & 192 & 496 & 899 \\
\hline São Paulo & 349 & 280 & 1.306 & 1.935 \\
\hline Paraná & 63 & 291 & 1.962 & 2.316 \\
\hline Santa Catarina & 112 & 414 & 982 & 1.508 \\
\hline Rio G. do Sul & 95 & 468 & 1.287 & 1.850 \\
\hline Mato G. do Sul & 36 & 850 & 342 & 1.228 \\
\hline Mato Grosso & 42 & 924 & 725 & 1.691 \\
\hline Goiás & 79 & 1.803 & 721 & 2.603 \\
\hline Distrito Federal & 4 & 2.390 & 95 & 2.489 \\
\hline Brasil & 2.374 & 8.976 & 24.409 & 35.759 \\
\hline
\end{tabular}

Fonte IBGE Estatísticas da Saúde Assistência Médico Sanitária $2002^{12}$ 
territorialização permitiu a abordagem familiar e comunitária dos problemas de saúide assim como o estabelecimento de vínculo entre os profissionais de saúde e o usuário.

Pode-se concluir que o investimento realizado pelo país na construção de uma ampla rede básica ao longo de quase oito décadas representa um patrimônio importante para a população brasileira e possibilita ao SUS o desenvolvimento de uma política nacional para a Atenção Primária à Saúde, independente das críticas ao modelo assistencial, aos percalços do ponto de vista do seu financiamento ou, ainda, às dificuldades de se localizarem ali os profissionais formados e capacitados na especialidade. Não se pode, portanto, desprezar o investimento material e, principalmente, humano, sempre crescente, o que pode representar a possibilidade de ser alcançar a eqüidade, a universalidade e a integralidade.

As tendências atuais serão discutidas a seguir e refletem as medidas recentes do poder público com relação ao financiamento e ao desen-

Tabela 3. Equipes de Saúde da Família por estado da Federeção - 1999-2002-2005 - MS/2006:

\begin{tabular}{|c|c|c|c|c|c|}
\hline Estados & 1999 & 2002 & $\begin{array}{c}\% \\
\text { crescimento } \\
1999-2002 \\
\end{array}$ & 2005 & $\begin{array}{c}\% \\
\text { crescimento } \\
1999-2005\end{array}$ \\
\hline DF & 121 & 40 & 33 & 40 & 33 \\
\hline Goiás & 108 & 811 & 751 & 969 & 897 \\
\hline Mato Grosso Sul & 23 & 222 & 965 & 320 & 1.391 \\
\hline Mato Grosso & 36 & 344 & 956 & 445 & 1.236 \\
\hline Alagoas & 237 & 594 & 251 & 685 & 289 \\
\hline Bahia & 82 & 862 & 1.051 & 1.888 & 2.302 \\
\hline Ceará & 678 & 1.217 & 179 & 1.320 & 195 \\
\hline Maranhão & 37 & 549 & 1.484 & 1.427 & 3.857 \\
\hline Paraíba & 69 & 777 & 1.126 & 1.144 & 1.658 \\
\hline Pernambuco & 350 & 1.158 & 331 & 1.547 & 442 \\
\hline Piauí & 186 & 704 & 378 & 980 & 527 \\
\hline Rio G. Norte & 87 & 451 & 518 & 805 & 925 \\
\hline Sergipe & 72 & 387 & 538 & 486 & 675 \\
\hline Acre & 35 & 77 & 220 & 126 & 360 \\
\hline Amazonas & 38 & 283 & 745 & 417 & 1.097 \\
\hline Amapá & 2 & 28 & 1.400 & 90 & 4.500 \\
\hline Pará & 106 & 366 & 345 & 513 & 484 \\
\hline Rondonia & 85 & 110 & 129 & 162 & 191 \\
\hline Roraima & 6 & 70 & 1.167 & 82 & 1.367 \\
\hline Tocantins & 139 & 258 & 186 & 317 & 228 \\
\hline Espírito Santos & 36 & 318 & 883 & 471 & 1.308 \\
\hline Minas Gerais & 809 & 2.061 & 255 & 3.091 & 382 \\
\hline Rio de Janeiro & 90 & 814 & 904 & 1.185 & 1.317 \\
\hline São Paulo & 237 & 1.774 & 749 & 2.527 & 1.066 \\
\hline Rio G do Sul & 197 & 1.071 & 544 & 1.452 & 737 \\
\hline Santa Catarina & 84 & 470 & 560 & 939 & 1.118 \\
\hline Distrito Federal & 164 & 882 & 538 & 1.136 & 693 \\
\hline Brasil & 4.114 & 16.698 & 406 & 24.564 & 597 \\
\hline
\end{tabular}

Fonte: $M S / D A B(2006)^{13}$ 
volvivemnto da assistência básica no país.

\section{A Organização Atual da Atenção Primária à} Saúde no Brasil

AAtenção Primária à Saúde/Atenção Básica (APS/AB) no Brasil é uma atribuição das secretarias municipais de saúde. Desde o ano 2000, o Ministério da Saúde repassou aos municípios a tarefa de gerenciar, de forma plena, a APS/AB em suas dimensões administrativa, técnica, financeira e operacional. Compreendida como um dos níveis do sistema de saúde e um campo específico de atuação, foi definida como:

Conjunto de ações, de caráter individual ou coletivo, situadas no primeiro nível de atenção dos sistemas de saúde, voltadas para a promoção da saúde, a prevenção de agravos, o tratamento e a reabilitação (Brasil, 1999). ${ }^{14}$

Nesta definição está implícita a importância do cumprimento da integralidade, isto é, o atendimento de necessidades que vão desde a promoção da saúde da comunidade até ações de reabilitação. Há também a preocupação da integração entre as atividades assistenciais e clínicas voltadas para os indivíduos e as ações programáticas, segundo os segmentos da população.

Leis e decretos relativos a novas formas de financiamento e de gestão do sistema de saúde brasileiro melhoraram as condições para que o gestor municipal pudesse cumprir o preceito constitucional da integralidade. As mudanças na lógica de financiamento foram estabelecidas pela Norma Operacional Básica-96 (NOB-96). As resoluções concernentes à implantação, por um lado, do Piso de Atenção Básica (PAB), em seus componentes fixo e variável e, por outro, da Programação Pactuada da Epidemiologia e Controle de Doenças (PPI - ECD) foram os principais mecanismos desta mudança.

O Piso de Atenção Básica (PAB) estabeleceu um valor que os municípios tinham direito a receber, fundo a fundo, do Governo Federal. Tal quantia variava entre 12,50 reais e 18 reais por habitante, uma vez cumpridos alguns requisitos prévios, tais como o funcionamento do Conselho Municipal de Saúde, a abertura de uma conta no Fundo Municipal de Saúde destinado à Atenção Básica, a existência de equipes técnicas no município, a assinatura de termos de compromisso etc. Outros incentivos fizeram parte do PAB, a serem distribuídos aos municípios habilitados para desenvolver outras ações de saúde no âmbito da APS/AB, tais como o Programa de Saúde da Família, a Farmácia Básica, o Incentivo às Ações de Combate às Carências Nutricionais, o Incentivo às Ações Básicas de Vigilância Sanitária, o Incentivo às Ações de Controle da Tuberculose, Incentivo Adicional ao Programa de Agentes Comunitários de Saúde, Incentivo à Saúde Bucal, Intensificação à Vigilância e Controle da Tuberculose, Medicamen- tos de Saúde Mental e Programa de Expansão à Saúde da Família, dentre outros. A lógica de paga- mento considerando o número de habitantes foi um avanço com relação às formas antigas de financiamento que privilegiavam regiões com muitas unidades de saúde, em detrimento dos municípios carentes, sem produção de serviços médico-hospitalares. Também a Programação Pactuada e Integrada de Epidemiologia e Controle de Doenças (PPI-ECD), atual PPIVigilância da Saúde, constituiu-se em um recurso 
repassado pelo Governo Federal a estados e municípios para o cumprimento de ações de controle de doenças e a operação de sistemas de vigilância epidemiológica e ambiental.

A NOB-96 permitiu que sistemas locais de saúde passassem a dispor de recursos desvinculados da realização de procedimentos diagnósticos e terapêuticos. Os sistemas começaram a receber recursos globais, segundo aspectos como perfil populacional, indicadores sanitários e epidemiológicos, desigualdades regionais, metas de cobertura, desempenho etc. Foi estabelecido que o gestor municipal planejasse ações voltadas para a melhoria das condições de saúde, segundo a evolução de indicadores sanitários e epidemiológicos. Assim, coube ao município pactuar, por exemplo, a redução da prevalência de determinadas doenças ou o aumento da cobertura vacinal ou pré-natal. Buscava-se, em suma, estabelecer um sistema de financiamento centrado mais em metas de desempenho, cobertura e impacto epidemiológico do que na produção de consultas ou internações.

O processo de pactuação de metas de cobertura e desempenho e o respectivo repasse financeiro exigiram a participação dos Conselhos Municipais de Saúde, os quais deveriam referendar e registrar em ata os compromissos assumidos pelos gestores locais, com uma maior transparência das ações de governo no setor. Em seguida, os pleitos municipais teriam de ser submetidos à instância estadual, analisados e, aprovados na Comissão Intergestora Bipartite, um conselho de gestores municipais e a Secretaria de Saúde do respectivo estado. O mesmo processo se dá no âmbito federal, na Comissão Intergestora Tripartite.
Anualmente as atividades desenvolvidas nos municípios passaram a ser avaliadas e monitoradas por meio de um conjunto de indicadores que buscam medir a cobertura, o desempenho e o impacto das ações sobre a saúde da população. O quadro a seguir descreve os indicadores principais para a Avaliação do Pacto da Atenção Básica. É fundamental destacar a importância desses processos de pactuação de compromissos mútuos entre os diversos níveis de governo. Tais negociações possibilitaram um maior diálogo entre os vários níveis de gestão e a comunidade, uma maior transparência na utilização dos recursos públicos e exigiram das equipes de saúde um maior compromisso com o resultado de seu trabalho.

\section{PACTO DAATENÇÃO BÁSICA}

Indicadores MS - 2004

01. Número absoluto de óbitos em menores de um ano de idade;

02. Taxa de mortalidade infantil;

03. Proporção de nascidos vivos com baixo peso ao nascer;

04. Proporção de óbitos em menores de um ano por causas mal definidas;

05. Taxa de internações por Infecção Respiratória Aguda em menores de cinco anos de idade;

06. Homogeneidade da cobertura vacinal por tetravalente em menores de um ano de idade;

07. Taxa de mortalidade materna;

08. Proporção de nascidos vivos de mães com quatro ou mais consultas de pré-natal;

09. Proporção de óbitos em mulheres em idade fértil investigados;

10. Razão entre exames citopatológicos cérvico- 
vaginais em mulheres de 25 a 49 anos e a população feminina nesta faixa etária;

11. Taxa de internação por acidente vascular cerebral;

12. Taxa de mortalidade por doenças cerebrovasculares;

13. Proporção de internação por cetoacidose e coma diabético;

14. Proporção de abandono do tratamento da tuberculose;

15. Proporção de abandono do tratamento da hanseníase;

16. Taxa de detecção de casos de hanseníase;

17. Cobertura da primeira consulta odontológica;

18. Razão entre os procedimentos odontológicos coletivos e a população de 0 a 14 anos;

19. Proporção da população coberta pelo Programa de Saúde da Família;

20. Média anual de consultas médicas nas especialidades básicas por habitante.

Fonte: MS/DAB (2006) $)^{15}$

Para a definição das taxas ou índices dos indicadores propostos no quadro acima, levou-se em consideração uma série de fatores, de forma a tornar factível o seu cumprimento por parte dos municípios. Para a definição da meta a ser cumprida a cada ano, tomou-se uma base histórica, considerando-se os níveis de desempenho alcançados e a situação dos programas e da assistência em cada realidade local. Coube ao estado o acompanhamento deste desempenho, bem como a prestação de assessoria técnica para que os municípios pudessem desempenhar suas tarefas de forma satisfatória e alcançar o êxito pretendido. Quanto aos recursos vinculados ao Governo Federal coube ainda, a Estados e Municípios, a alocação, como contra-partida, de recursos próprios de seus orçamentos fiscais. Se forem considerados os recursos obrigatórios a serem gastos por estados e municípios, de seus respectivos orçamentos fiscais, estes percentuais deveríam alcançar, segundo a nova legislação, cerca de $30 \%$ do repasse federal. Dessa forma, o financiamento à saúde passou a envolver recursos dos três níveis de governo. Levantamento realizado por Ribeiro ${ }^{16}$ demonstrou o percentual de recursos destinados pelo Ministério da Saúde à APS/AB no país. Este representava um terço dos gastos com hospitais e ambulatórios de média e alta complexidade. Esse percentual pode ser considerado alto, haja vista que, historicamente, a APS/ $A B$ esteve sempre relegada a segundo plano, do ponto de vista do financiamento, representando menos de $10 \%$ do gasto em saúde no país.

A tabela 4 revela ainda algumas disparidades entre regiões que devem ser superadas. Atualmente, há uma unanimidade entre os gestores federal, estadual e municipal em priorizar a APS / $A B$ no país, de forma a racionalizar o uso de recursos hospitalares, aumentar a satisfação do usuário e das comunidades com os serviços de saúde e melhorar o controle de doenças, tais como a dengue, a tuberculose, a AIDS etc.

As tendências mais recentes da lógica organizacional da APS/AB enfatizam o modelo implantado desde meados da década de 1990. No aspecto do financiamento, este se consolida como prioritário, em patamares que ultrapassam em muito os valores historicamente destinados ao subsetor. Também o Pacto pela Saúde 2006 reitera e 
aprofunda as prioridades estabelecidas para a APS/ $A B$. Esse tema, porém, escapa ao escopo deste artigo.

\section{Conclusão}

A trajetória da organização da APS/AB no país em 90 anos de história tem como principais características a sua permanência e continuidade. Houve momentos em que esta organização experimentou crescimento e dinamismo, alternados por períodos de estagnação e impasse. Foram três os momentos de crescimento: a implantação dos Centros de Saúde, entre 1926 e 1942; o movimento da Atenção Primária à Saúde e da Reforma Sani- se pode concluir que este campo da atuação da Saúde Pública no Brasil esteve pautado exclusivamente por um ideário liberal ou como uma política residual. Tampouco o grau de abrangência, relevância e cobertura alcançado se coadunam como uma possível estratégia governamental de focalização. Os impasses que hoje estão colocados para que a APS/AB atinja a universalidade e se consolide como eixo central da política de saúde estão mais na dependência dos interesses privados que sempre se interpuseram na luta pelo Sistema Único de Saúde no país do que na capacidade técnica, política e administrativa dos seus gestores e provedores.

O sistema de financiamento dos recursos

Tabela 4. Procedimentos ambulatoriais, transferências federais, SUS. Valor em reais aprovado por categoria segundo a região x 1000 - IBGE - Brasil - 2000

\begin{tabular}{lrrc}
\hline Região & Atenção Básica & Média e Alta & Percentual AB/MA \\
\hline Norte & 73777,32 & 187738,84 & 39,30 \\
Nordeste & 330156,57 & 1008477,80 & 32,74 \\
Sudeste & 539113,37 & 2359709,73 & 22,85 \\
Sul & 180278,55 & 658526,17 & 27,80 \\
Centro Oeste & 86252,16 & 284219,01 & 30,35 \\
\hline Total & 1209577,97 & 4488671,55 & 26,95 \\
\hline
\end{tabular}

Fonte: Adaptado de Ribeiro et alli, 20016

tária, entre 1978 e 1986, e a implantação do Programa de Saúde da Família, especialmente a partir da promulgação da NOB-96. Sem referência neste texto, é importante citar o movimento da medicina preventiva que, na década de 1960, buscou a revitalização dos Centros de Saúde. Mesmo considerando que a APS/AB no país sempre foi marcada por uma forte prioridade na atuação sobre as camadas menos favorecidas da população, não oriundos do $\mathrm{PAB}$ induziram a uma reorganização da forma de atenção. Contemplaram-se com mais recursos os municípios que implantaram formas de assistência inovadoras tais como as equipes de Saúde da Família, a assistência ao desnutrido, a farmácia básica, os centros de controle de zoonoses, os núcleos de Vigilância da Saúde etc. Essa nova metodologia de repasse de recursos exigiu uma maior participação de gestores e comunidades 
no planejamento e na avaliação das ações de saúde municipais e contribuiu, ainda, para ampliar e qualificar, por meio dos Conselhos Municipais de Saúde, o controle social exercido por esses fóruns e, para conformar, ainda por meio desses ConseIhos, o interesse coletivo pela garantia de atenção integral ${ }^{17}$.

\section{Referências:}

1.Braga JCS, Paula SG. Saúde e Previdência. Estudos de Política Social. São Paulo, Rio de Janeiro: Cebes, Hucitec; 1981. 226 p.

2. Chagas Filho C. Meu Pai. Rio de Janeiro: Editora FIOCRUZ; 1993. $316 \mathrm{p}$.

3. Castro-Santos LA, Faria LR. Arquivo Rockefeller, Banco de dados 1920-1925. Rio de Janeiro: IMS; 1996. 92 p. (Série estudos de saúde coletiva, n. 143). 4. Fraga C. Introdução ao relatório dos serviços do Departamento Nacional de Saúde Pública. Archivos de Hygiene. 1928; Ano II (1): 221-224.

5. Barros Barreto J, Fontenelle JP. O systema de centros de saúde no Rio de Janeiro. Archivos de Hygiene. 1935; Ano V (1): 83-115.

6. Barros Barreto J. A organização da saúde pública no Brasil. Arquivos de Higiene. ago. 1942; Ano 12, (2): 169-215.

7.Elias P, Cohn A. Saúde no Brasil. Políticas e Organização de Serviços. São Paulo: Cortez/ CEDEC; 1996. 117p.

8. Sala AA. A avaliação de programas de saúde. In: Programação em Saúde Hoje. São Paulo: Hucitec; 1993. 224p.

9. Franco TB. O Acolhimento e os processos de trabalho em saúde: o caso de Betim (MG). Betim (MG): [s.n.]; 1996. 25p. (mimeo.).

10. Merhy EE. Crise do modo de se produzir saúde: uma discussão do modelo assistencial e o trabalho médico no Brasil. [s.l.:s.n.]; 1996. 10p. (mimeo.). 11. Viacava F, Bahia L. Assistência Médico-Sanitária: Os serviços de saúde segundo o IBGE. DADOS. Nov. 1996; (20): 1-30.

12. IBGE. Estatísticas da saúde: assistência médico-sanitária. Rio de Janeiro: IBGE; 2002. 303p. 13. BRASIL, Ministério da Saúde, DAB, Histórico da Saúde da Família no Brasil:

http://dtr2004.saude.gov.br/dab/documentos/ historico_psf/historico. Acesso em 12/10/2006 14. BRASIL. Ministério da Saúde. Manual para a Organização da Atenção Básica. Brasília (DF): Ministério da Saúde; 1999. 40p.

15. BRASIL, Ministério da Saúde, DAB, Pacto de Indicadores da Atenção Básica:

http://dtr2004.saude.gov.br/dab/documentos/ informes/psfinfo19.pdf Acesso em 12/10/2006 16. Ribeiro JM et al. Atenção Básica no sistema único de saúde e indicadores para o município do Rio de Janeiro. Saúde em Foco. jul. 2001; (21): 35-59.

17. Carvalho $\mathrm{G}$. Comentários à norma operacional da assistência à saúde. NOAS. [s.I.:s.n.]; 2001. 11p. (mimeo).

\section{Endereço para correspondência:}

Carlos Eduardo Aguilera Campos

Programa de Atenção Primária à Saúde PAPS/FM/UFRJ

Rua Laura Araújo 36, Cidade Nova, Rio de Janeiro, RJ - CEP: 20211-170

\section{Endereço Eletrônico:}

cadu@vetor.com.br 